\title{
THERAPEUTIC ERYTHROCYTAPHERESIS IN THE INITIAL TREATMENT OF HEREDITARY HEMOCHROMATOSIS
}

\author{
Vit Ǩeháček ${ }^{1}$, Milan Bláha ${ }^{2}$,Hana Jiroušová ${ }^{1}$, Jitka Černohorskál, Petr Papoušek ${ }^{1}$
}

Charles University in Prague, Faculty of Medicine and University Hospital Hradec Králové, Czech Republic: Transfusion Department ${ }^{1}$, 4th Department of Medicine, Hematology, Charles University in Prague, Faculty of Medicine and University Hospital in Hradec Králové 2

Summary: Background: The current treatment of hereditary hemochromatosis $(\mathrm{HH})$ consists of performing periodic whole blood phlebotomies. Erythrocytapheresis (EA) can remove up to three times more red blood cells per single procedure and could thus have a clinical benefit. A prospective study of 30 consecutive cases of $\mathrm{HH}$ were included in a periodic EA program. Methods and patients: EA were performed using a discontinuous flow cell separators. The protocol consisted of a bimonthly EA until normalization of the serum ferritin was reached. The aim was to reduce the total erythrocyte volume by $25-35 \%$, eventually, to adjust the amount so that hematocrit would not drop below 0.25 . Results: $530 \pm 101 \mathrm{ml}$ of erythrocytes were removed (median 517, range 116-761 ml). Iron depletion (ferritin $<20 \mu \mathrm{g} / \mathrm{l}$ ) was achieved in all patients after a mean $6.9 \pm 7.6$ months, median 5 months, range 1-36 months and a mean 14 EA sessions. The procedures were well tolerated and there were no severe side-effects. Conclusions: We conclude that HH patients treated with EA achieved iron depletion quickly under good conditions of tolerance. The efficacy, speed, tolerability, and more favorable schedule of an EA program facilitate treatment of $\mathrm{HH}$.

Key words: Hereditary hemochromatosis; HFE-gene; Phlebotomy; Therapeutic Erythrocytapheresis

\section{Introduction}

Hereditary hemochromatosis $(\mathrm{HH})$ remains the most common, identified genetic disorder in Caucasians. Although its geographic distribution is worldwide, it is seen most commonly in populations of northern European origin, particularly, Nordic or Celtic ancestry in which it occurs with a prevalence of approximately 1 per 220-250 individuals (2). $\mathrm{HH}$ is characterized by an increase in iron absorption from the gastrointestinal tract, leading to the accumulation of iron in many organs and tissues $(9,10,17)$. Because withdrawal of blood is the most effective way to reduce iron storage in the body, the preferred treatment for iron overload associated with hemochromatosis is therapeutic phlebotomy (1, $4,5,26)$. This causes iron mobilization for incorporation into hemoglobin $(\mathrm{Hb})$ during erythropoiesis (18). Once a serum ferritin level of less than $50 \mu \mathrm{g} / \mathrm{l}$ and/or a transferrin saturation below 50 percent is reached, blood lettings can be reduced from three to six times a year (13). Erythrocytapheresis (EA) may be a good alternative for therapeutic phlebotomy (21-23). By means of EA at least $400 \mathrm{ml}$ of red blood cells (RBC) can be collected at once (but twice as this amount may also be removed) which reduces the number of treatments. Only the RBCs are collected, and the plasma including all proteins, coagulation factors, white blood cells, thrombocytes, and replacement fluid are returned to the patient (13). Apparently, the therapy with EA in clinically developed $\mathrm{HH}$ has its priorities, in practice its main problem is the cost. Although 20 years have passed since the first trials of EA utilization in HH therapy, the situation still remains unresolved. Several studies have been published but especially economic calculations among the countries are different. There are no unified procedural standards for EA because of various details in individual workplaces. In this study we inform of the results with EA in HH therapy using our scheme and our modification under our conditions.

\section{Patients and methods}

\section{a) Patient characteristics}

In the recent 5 years 24 patients suffering from increased ferritin and suspected $\mathrm{HH}$ have been referred to our department from other clinics of the University Hospital. (The University Hospital provides care for about 1.5 milion inhabitants of the Czech Republic.) In 20 of these patients a mutation of the hemochromatosis gene had been detected - it was C282 in all of them in homozygous form. We searched for this mutation in their close relatives: 6 persons were examined and 5 of them had C282Y mutation (homozygous for 3 patients). Two patiens had increased ferritin levels and increased transferrin saturation and were assigned for EA therapy. Thus, a group of 22 persons homozygous for C282Y mutation was formed, for basic data see Table 1 . 
Tab. 1: Patients treated with EA

\begin{tabular}{|c|c|c|c|c|c|c|}
\hline Patient & Sex & Age & $\begin{array}{c}\text { HFE-gene } \\
\text { mutation }\end{array}$ & Height & Weight & $\begin{array}{c}\text { Total blood } \\
\text { volume }\end{array}$ \\
\hline 1 & o & 52 & $\mathrm{C} 282 \mathrm{Y} / \mathrm{C} 282 \mathrm{Y}$ & 182 & 85 & 5680 \\
\hline 2 & $q$ & 50 & $\mathrm{C} 282 \mathrm{Y} / \mathrm{C} 282 \mathrm{Y}$ & 166 & 55 & 3774 \\
\hline 3 & $\sigma^{1}$ & 37 & $\mathrm{C} 282 \mathrm{Y} / \mathrm{C} 282 \mathrm{Y}$ & 180 & 80 & 5480 \\
\hline 4 & $\hat{\sigma}$ & 52 & C282Y/C282Y & 173 & 70 & 5025 \\
\hline 5 & q & 62 & $\mathrm{C} 282 \mathrm{Y} / \mathrm{C} 282 \mathrm{Y}$ & 160 & 80 & 4469 \\
\hline 6 & $\hat{0}$ & 55 & C282Y/C282Y & 178 & 83 & 5551 \\
\hline 7 & o & 44 & $\mathrm{C} 282 \mathrm{Y} / \mathrm{C} 282 \mathrm{Y}$ & 190 & 105 & 6450 \\
\hline 8 & $\hat{0}$ & 37 & $\mathrm{C} 282 \mathrm{Y} / \mathrm{C} 282 \mathrm{Y}$ & 185 & 70 & 5197 \\
\hline 9 & $\hat{0}$ & 53 & $\mathrm{C} 282 \mathrm{Y} / \mathrm{C} 282 \mathrm{Y}$ & 185 & 90 & 5893 \\
\hline 10 & $\sigma^{1}$ & 52 & $\mathrm{C} 282 \mathrm{Y} / \mathrm{C} 282 \mathrm{Y}$ & 175 & 80 & 5403 \\
\hline 11 & $\sigma^{1}$ & 62 & $\mathrm{C} 282 \mathrm{Y} / \mathrm{C} 282 \mathrm{Y}$ & 172 & 72 & 5082 \\
\hline 12 & $\pi$ & 56 & $\mathrm{C} 282 \mathrm{Y} / \mathrm{C} 282 \mathrm{Y}$ & 170 & 80 & 5326 \\
\hline 13 & q & 52 & $\mathrm{C} 282 \mathrm{Y} / \mathrm{C} 282 \mathrm{Y}$ & 168 & 95 & 4990 \\
\hline 14 & 0 & 50 & $\mathrm{C} 282 \mathrm{Y} / \mathrm{C} 282 \mathrm{Y}$ & 180 & 110 & 6426 \\
\hline 15 & 0 & 55 & $\mathrm{C} 282 \mathrm{Y} / \mathrm{C} 282 \mathrm{Y}$ & 182 & 95 & 6005 \\
\hline 16 & $\hat{0}$ & 60 & $\mathrm{C} 282 \mathrm{Y} / \mathrm{C} 282 \mathrm{Y}$ & 174 & 82 & 5455 \\
\hline 17 & $\delta$ & 34 & $\mathrm{C} 282 \mathrm{Y} / \mathrm{C} 282 \mathrm{Y}$ & 185 & 114 & 5632 \\
\hline 18 & $q$ & 62 & $\mathrm{C} 282 \mathrm{Y} / \mathrm{C} 282 \mathrm{Y}$ & 164 & 64 & 4047 \\
\hline 19 & q & 49 & $\mathrm{C} 282 \mathrm{Y} / \mathrm{C} 282 \mathrm{Y}$ & 155 & 54 & 3614 \\
\hline 20 & $\hat{0}$ & 46 & $\mathrm{C} 282 \mathrm{Y} / \mathrm{C} 282 \mathrm{Y}$ & 180 & 98 & 6065 \\
\hline 21 & j & 73 & $\mathrm{C} 282 \mathrm{Y} / \mathrm{C} 282 \mathrm{Y}$ & 171 & 77 & 5240 \\
\hline 22 & $q$ & 47 & $\mathrm{C} 282 \mathrm{Y} / \mathrm{C} 282 \mathrm{Y}$ & 170 & 74 & 4430 \\
\hline
\end{tabular}

The mean initial level of ferritin in the patients was $1358.1 \pm 921.4 \mu \mathrm{g} / \mathrm{l}$, median $1105.0 \mu \mathrm{g} / \mathrm{l}$ (Graph 1). Initial values of iron, binding capacity and transferrin saturation are in Table 2.

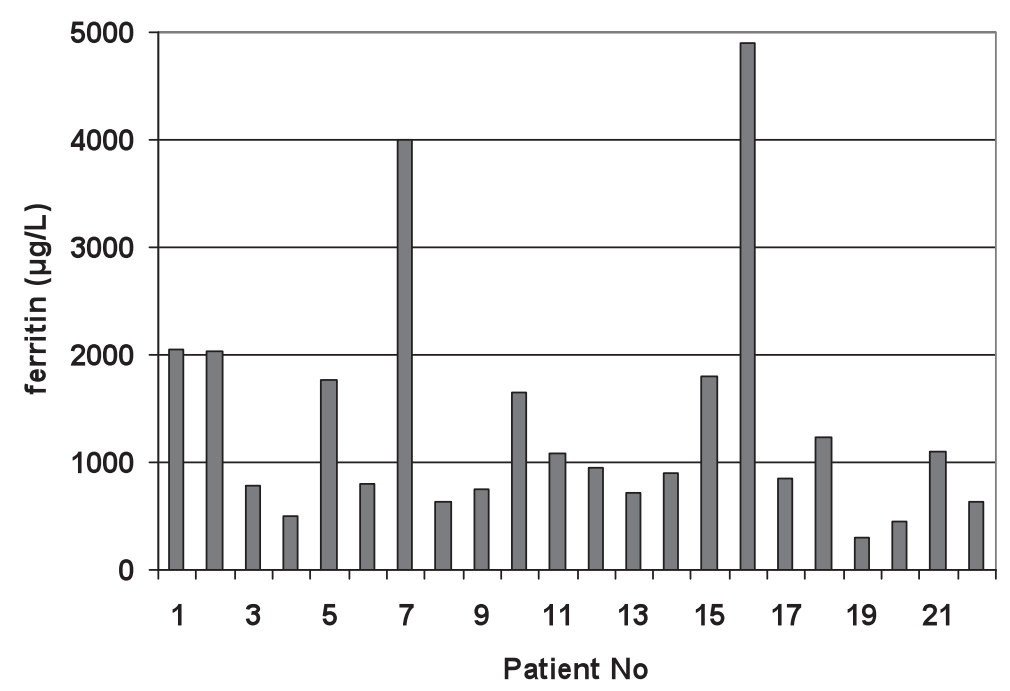

Graph 1: Initial ferritin values 
Tab. 2: Initial values of ferritin, iron, binding capacity and saturation of transferrin

\begin{tabular}{|l|c|c|c|c|}
\hline & AV \pm SD & Median & Range & Normal value \\
\hline $\begin{array}{l}\text { Ferritin } \\
(\mu \mathrm{g} / \mathrm{L})\end{array}$ & $1358.1 \pm 921.4$ & 1105.0 & $292.3-4899.3$ & $\begin{array}{c}14-150 \text { women } \\
17-230 \text { men }\end{array}$ \\
\hline Iron $(\mu \mathrm{mol} / \mathrm{L})$ & $34.9 \pm 9.5$ & 32.0 & $197-49.5$ & $5.83-34.5$ \\
\hline $\begin{array}{l}\text { Binding capacity } \\
(\mu \mathrm{mol} / \mathrm{L})\end{array}$ & $47.1 \pm 6.8$ & 48.5 & $34.4-58.3$ & $40.8-76.6$ \\
\hline $\begin{array}{l}\text { Transferrin } \\
\text { Saturation }\end{array}$ & $0.74 \pm 0.22$ & 0.84 & $0.40-0.96$ & $0.20-0.55$ \\
\hline
\end{tabular}

Legend: $\mathrm{AV}=$ mean; $\mathrm{SD}=$ standard deviation

\section{b) Individualized treatment strategy}

- Erythrocytaphereses were performed on the separator Haemonetics MCS+ (Haemonetics Corp., Braintree MA, USA), software version EN-990923 (further only MCS+) with disposable closed collection set TAE 944

- Total blood volume (TBV) was determined based on sex, height and weight of each patient using the MCS+ calculator

- Total erythrocyte volume (TEV) calculated according to the formula:

Volume of erythrocytes $(\mathrm{ml}) \mathrm{TEV}=\mathrm{TBV} \times$ hematocrit

- The amount of removed erythrocytes was determined in the range between $25-35 \%$ of the total erythrocyte volume (TEV), eventually, we had to adjust the removed amount so that the post-collection hemotocrite (HT) would not drop below 0.25

- We assessed compensation mechanisms of each patient based on clinical examinations (patient history, condition of cardiovascular and pulmonary systems and other somatic findings, laboratory results) and, if necessary, corrected the volume of removed erythrocytes

- Before further procedures we tried to find out about individual collection tolerance and searched for late post-collection effects. When they appeared, the volume was corrected in subsequent treatment sessions

- After reaching the ferritin target value below 25-50 $\mu \mathrm{g} / 1$, induction phase was discontinued and the patient was assigned to the maintenance phase

\section{c) Laboratory examinations}

Basic biochemical and hematologic profile was determined in all patients. Examinations regularly performed during the EA therapy:

- Prior to EA: blood count, iron level, transferrin binding capacity for iron, transferrin and ferritin saturation

- Post collection: blood count

All used examination methods were performed by accredited laboratories of the University Hospital:

- Blood count - NK Celltac Alfa apparatus (Nihon Kohden, Tokyo, Japan)
- Iron level - colorimetric method on Cobas Modular analyzer (Roche, Basel, Switzerland), normal values (NV): 5.83-34.5 $\mu \mathrm{mol} / 1$

- Transferrin binding capacity for iron - spectrometrophotometric method on Dohas Modular (Roche, Basel, Switzerland), NV of unsaturated iron binding capacity (UIBC): 24.2-70.1 $\mu \mathrm{mol} / 1$ (women), 22.3-61.7 $\mu \mathrm{mol} / 1$ (men)

- Total iron binding capacity (TIBC) was determined as a sum of iron level and UIBC. NV: 40.8-76.6 $\mu \mathrm{mol} / 1$ (men and women)

- Transferrin saturation was calculated as a proportion of iron and TIBC. NV: $0.20-0.55$

- Ferritin level was determined by an enzyme microanalysis on microparticles MEIA with Abbott AxSYM apparatus (Abbott Laboratories Diagnostics Division, Abbott Park, IL, USA) at the Department of Nuclear Medicine, University Hospital, Hradec Králové. NV: 14-150 g/1 (women) and 17-230 $\mu \mathrm{g} / \mathrm{l}$ (men)

- HFE-gene mutation was examined by genotypic analysis of restricted fragments

\section{Results}

A total of 311 therapeutic erythrocytapheresis sessions were performed (231 in men, 80 in women), mean 14 , median 7.5 , range $2-70$. Per single erythrocytapheresis $530 \pm 101 \mathrm{ml}$ of erythrocytes were removed (median 517 , range $116-761 \mathrm{ml}$ ). The mean volume of withdrawn erythrocytes was $548 \pm 105 \mathrm{ml}$ in men and $481 \pm 71 \mathrm{ml}$ in women, i.e. TEV removed in one session was $24.1 \pm$ $3.5 \%$ in men (median $22.8 \%$, range $19.9-30.9$ ) and 31.0 $\pm 5.4 \%$ in women (median $31.0 \%$, range $23.8-37.4$ ). The therapy lasted $6.9 \pm 7.6$ months, median 5 months, range 1-36 months.

The aim of therapy was fulfilled in 19 of 22 patients - the reached ferritin level was below $50 \mu \mathrm{g} / \mathrm{l}$. At the end of therapy the mean ferritin level was $19.4 \pm 11.1 \mu \mathrm{g} / 1$ (median 14.7 , range $6-44.3 \mu \mathrm{g} / \mathrm{l}$. In 14 patients the ultimate ferritin level was lower than $25 \mu \mathrm{g} / \mathrm{l}$, in 10 patients ferritin dropped below $15 \mu \mathrm{g} / \mathrm{l}$ after the last collection (Table 3 ). The drop of ferritin well correlated with the volume of removed 
erythrocytes $(r=0.70)$. In 3 patients the treatment could not be finished - twice the therapy was discontinued due to health reasons, once due to the change of the patient's address. Transferrin saturation decreased from $0.74 \pm 0.22$ of original value to $0.19 \pm 0.06$ after the treatment was finished.

Tab. 3: Ferritin level, binding capacity, transferrin and ferritin saturation at the end of therapy

\begin{tabular}{|l|c|c|c|c|}
\hline & AV $\pm \mathrm{SD}$ & Median & Range & Normal value \\
\hline Iron $(\mu \mathrm{mol} / \mathrm{L})$ & $12.9 \pm 5.7$ & 11.6 & $7.0-24.6$ & $5.83-34.5$ \\
\hline $\begin{array}{l}\text { Binding capacity } \\
(\mu \mathrm{mol} / \mathrm{L})\end{array}$ & $62.2 \pm 9.1$ & 64.6 & $48.7-70.9$ & $40.8-76.6$ \\
\hline $\begin{array}{l}\text { Transferrin } \\
\text { saturation }\end{array}$ & $0.20 \pm 0.06$ & 0.22 & $0.10-0.26$ & $0.20-0.55$ \\
\hline $\begin{array}{l}\text { Ferritin } \\
(\mu \mathrm{mol} / \mathrm{L})\end{array}$ & $19.4 \pm 11.1$ & 14.7 & $6.0-44.3$ & $\begin{array}{c}14-150 \text { women } \\
17-230 \text { men }\end{array}$ \\
\hline
\end{tabular}

Legend: $\mathrm{AV}=$ mean; $\mathrm{SD}=$ standard deviation

During 311 collections 33 complications were recorded $(10.6 \%)$ of which 32 were not serious (two vein ruptures, three vasovagal reactions and 27 were signs of light citrate toxicity. Once the session had to be interupted due to technical reasons (separator trouble). Except administration of a calcium effervescent tablet no drug therapy was necessary for post-collection reactions. The therapy had never to be interrupted due to medical reasons.

\section{Discussion}

$\mathrm{HH}$ is a hereditary disease, its occurrence is more frequent than was previously thought (24). This is necessary to keep in mind because $\mathrm{HH}$ symptoms are not pathognomic. But when $\mathrm{HH}$ is kept in mind, laboratory diagnosis is not difficult. After diagnosis is confirmed, quick and effective therapy should follow because its delay influences prognosis $(2,18)$. In $\mathrm{HH}$ the performance of periodic phlebotomies has been shown to be effective in obtaining iron depletion and, with it, an improvement in these patients' symptoms and prognosis (4). Phlebotomy as one of the few therapeutic methods has been used for centurie (but in other indications). It is simple and cheap. That is why phlebotomy is the preferred metod all the time $(6,9)$. In recent years several studies have emerged dealing with erythrocytapheresis utilization, and, mostly the method was evaluated as clinically very effective $(16,20-23)$. The authors confirm that a short interval is needed from the therapy initiation to reach target values (ferritin $<50 \mu \mathrm{g} / \mathrm{l}$ ) - less than a year - whereas with phlebotomy the time of therapy is much longer. In patients with severe iron overload, more than 2 years may be required, leading to anemic fatigue and lack of compliance (20). In our study EA therapy (1 session in 10-14 days) lasted $6.9 \pm 7.6$ months on the average. The mean ferritin value at the end of therapy was $19.4 \pm$ $11.1 \mu \mathrm{g} / \mathrm{l}$ and enabled the pass into EA maintenance therapy -1 session in 2-6 months.
We mentioned above that phlebotomy is still considered the first line in the HH therapy. Lower technical, medical, and economic demands of phlebotomy would still have a decisive role in the near future. Despite this, phlebotomy may also carry a number of complications. In 1997 Moirand et al. described complications in 64\% of 353 patients treated with phlebotomy. Complications included problems with venous access in $43 \%$ of the patients, fatigue in $63 \%$ of patients, and $28 \%$ of patients complained about inconvenience of the therapy, $8 \%$ of patients considered regular phlebotomy as an unpleasant intervention into their personal life, and $6 \%$ of patients a serious intervention into their professional life (15). Our experience is similar to the experience of Rombout-Sestrienkova that after a longer time more than one half of the patients found regular phlebotomy troublesome and discomforting. Nearly two thirds of the patients did not agree with weekly phlebotomy and required reduction of their frequency (22). Two deaths after phlebotomy as a most serious complication were described $(8,11)$.

Not without importance is the fact that collection needle for erythrocytapheresis is of 1-2 gauges thinner than for phlebotomy. A greater diameter increases the risk of hematomas and damage to artery or nerve fibres $(7,19)$.

At phlebotomy, except erythrocytes, also plasma containing thrombocytes, coagulation factors and proteins is removed which may be harmful for patients with hypoproteinemia or thrombocytopenia $(21,22)$. Hypoproteinemia may unfavorably influence patients with $\mathrm{HH}$ and liver cirrhosis (14). At erythrocytapheresis erythrocytes are removed and all other components are returned to the patient's circulation. The loss of plasma at phlebotomy may be clinically very important. The recommended frequency of phlebotomy is 1-2 times a week. Provided that the patient's hematocrite is $0.35-0.45$ than $275-325 \mathrm{ml}$ of plasma is removed. If the phlebotomy is accomplished weekly then the loss of plasma could be up 17.2 liters; if 
the phlebotomy is more frequent ( 2 a week) and hematocrite 0.35 than the loss of plasma can reach 32.4 liters. This volume of plasma is even higher than maximum plasma volume that may be removed from a healthy person in an intensive donor plasmapheretic program - i.e. 25 1/year (Guide to the preparation, use and quality assurance of blood components, 15th edition. Council of Europe Publishing, Strasbourg, 2010). As donor studies have shown, plasma collections near to $25 \mathrm{l} /$ year lead to a marked drop of total protein and immunoglobulins in healthy persons, and more than one third of donors $(40 \%)$ have to quit due to hypoproteinemia and hypogammaglobulinemia (25). The loss of plasma by erythrocytapheresis counts for $10 \%$ of the removed erythrocyte volume - in our group a mean $55 \mathrm{ml}$ of plasma were removed from men and $48 \mathrm{ml}$ from women.

To date the literature offers only limited reports about HH therapy with EA. They are mostly smaller non-randomized studies. A prospective randomized study would be ideal for comparing efficacy of EA vs. phlebotomy. In the U.S. Register NIH (National Institution of Health) 3 studies have been reported - from Norway, Italy, and the Netherlands. However, to date not even preliminary results of the first two studies have been published. The only prospective randomized study published is the study of
Rambout-Sestrienkova et al. from the year 2012 (21). Even economic evaluation included in the study showed unambiguous priority of EA in the therapy cost. In our study randomization of patients for phlebotomy was not possible. Instead, we performed a research probe in 3 patients (homozygous for C282Y) treated by phlebotomy in weekly intervals and compared the results with EA therapy. Hematocrit of these 3 patients fluctuated in the range $0.33-0.40$. $500 \mathrm{ml}$ withdrawn in one phlebotomy session contained $165-200 \mathrm{ml}$ of erythrocytes. Our conclusion is the same as the data presented till now that by erythrocytaphereses the mean removed $\mathrm{RBC}$ volume was three times higher. The relation of ferritin drop to erythrocyte volume was compared with data of patients treated by EA (Graph 2). The rate of drop in phlebotomy is significantly lower which is fully in agreement with the published data $(16,20-23)$.

The therapy intensity (EA at a 10-14 day interval) showed as sufficient, target values were reached in 6 months on the average and its compliance was $100 \%$. The treatment was discontinued only in 3 patients but not due to the bad compliance: $1 \times$ change of place of residence, $2 \times$ from healthy reasons ( 1 death of the patient, 1 patient with liver cirrhosis and long-term hospitalization). EA had only minimum side-effects, none were serious.

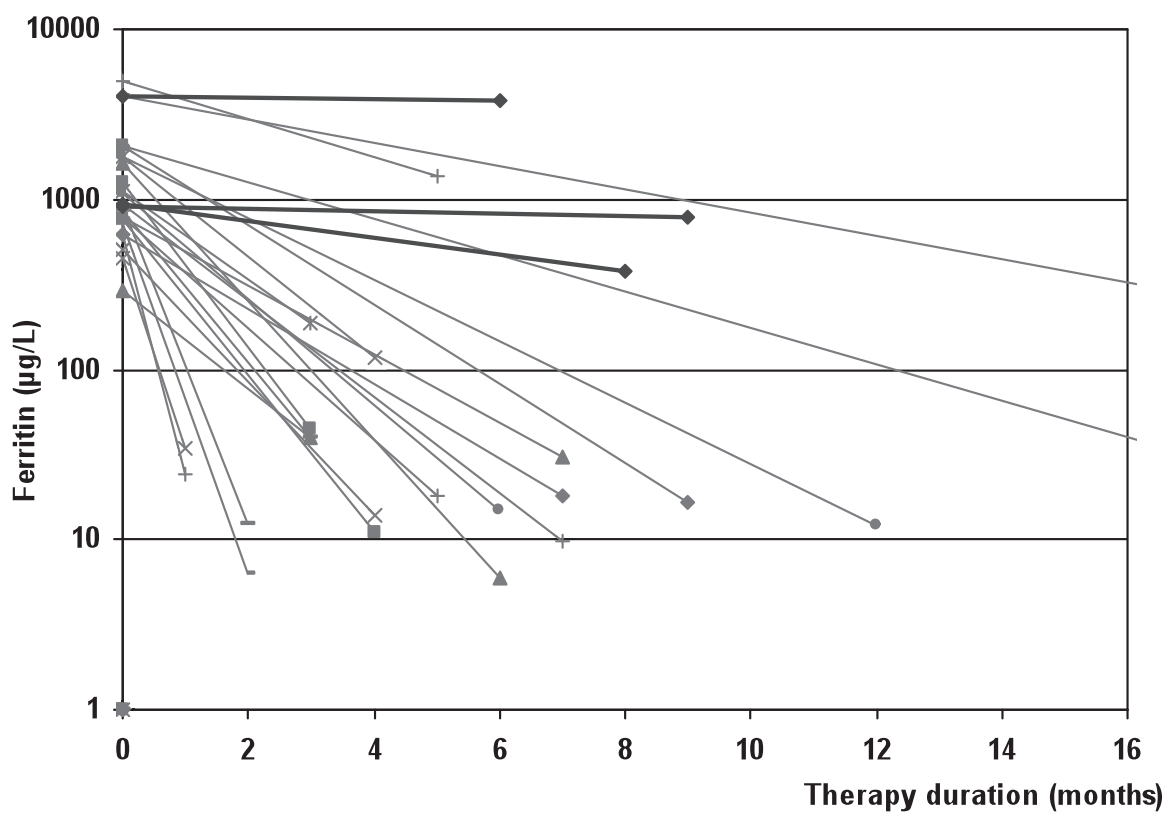

Graph 2: Comparison of ferritin drop in relation to therapy duration and therapy method. EA patients $(n=22$, thin line $)$, phlebotomy patients $(n=3$, thick line)

To date replacement of removed erythrocytes is a nonunified and unresolved problem. Replacement is not necessary when $500 \mathrm{ml}$ of blood is removed. In our study we used saline in the ratio $1.5: 1$ to erythrocyte volume. In patients with $\mathrm{HH}$ complications (such as liver cirrhosis) replacement fluid consisted of albumin (in 5\% solution)
+ saline as is commonly used at higher plasma collections - in exchange plasmaphereses (12).

A clinically interesting problem remains to find another simplier and more reliable markers for both diagnosis and therapy of HH. From this aspect the mean cell volume (MCV) seems to be interesting. Several authors assumed 
that mean cell volume (MCV) together with hemoglobin level is a simple and reliable marker important for treatment and follow-up of HH by phlebotomy (3). In our study $\mathrm{MCV}$ in patients did not significantly depend on erytrocyte volume that was removed. Statistically significant decrease of $\mathrm{MCV}$ was noted only in patients where ferritin level dropped below $15 \mu \mathrm{g} / \mathrm{l}$. Nevertheless, at the same time the drop of hemoglobin and hematocrit caused by iatrogenous sideropenia was also noted.

From the practical point of view economy is probably the most important and interesting issue. The literature data are scarce and differ in the cost of expended work and material among individual countries. Mostly, EA is considered a significantly more expensive. However, there are activities such as indirect expenses and loss of the patient's productivity that are counted to the cost, too. Then the situation is different. There is probably only one study presenting the details (21). These authors performed a cost price calculation. This approach is also known as microcosting which has the advantage of allowing others to see how well the analysis matches their own situation where patterns of care may differ. Hence, it becomes possible to compare volumes of use between different countries or settings and to examine whether a large cost difference between EA and phlebotomy is in fact related to real differences in resource use. This study documents that after the total calculation the difference between expenses on EA and phlebotomy are unimportant. In our study we have calculated only the cost of material which, in our country, is for EA unfavorable (about ten times more).

\section{Conclusion}

It is true that EA is the method requiring a well trained team and matching equipment but then is clinically very effective with only a low percentage of side effects that are not dangerous for the patient. The details are presented above.

\section{References}

1. Adams PC, Barton JC. How I treat hemochromatosis. Blood 2010; 22; 116(3): $317-25$.

2. Bacon BR, Adams PC, Kowdley KV, Powell LW, Tavill AS. Diagnosis and Management of Hemochromatosis: 2011 Practice Guideline by the American Association for the Study of Liver Diseases. Hepatology 2011; 54(1): 328-343.

3. Bolan CD, Conry-Cantilena C, Mason G, et al. MCV as a guide to phlebotomy therapy for hemochromatosis. Transfusion 2001; 41(6): 819-27.
4. Brissot P, Ball S, Rofail D, Cannon H, Jin VW. Hereditary hemochromatosis: patient experiences of the disease and phlebotomy treatment. Transfusion. 2011; 51(6): 1331-8.

5. Figura G, Kulaksiz H. Diagnosis and treatment in hereditary hemochromatosis. Deutsche Med Wochenschr 2009; 134(50): 2565-72.

6. Gan EK, Powell LW, Olynyk JK. Natural history and management of HFE-hemochromatosis. Semin Liver Dis 2011; 31(3): 293-301.

7. Hicken BL, Tucker DC, Barton JC. Patient compliance with phlebotomy therapy for iron overload associated with hemochromatosis. Am J Gastroenterol 2003; 98(9): 2072-7.

8. Hofstetter JR. Risks in blood-letting in therapy of hemochromatosis. Gastroenterologia 1957; 87(3-4): 186-91.

9. Horák J. a kol. Hemochromatóza. Praha: Grada Publishing, 2010: 232.

10. Horák J. Czech Hepatologic Society of the Czech Medical Society. The standard diagnostic and therapeutic method in genetic (hereditary) hemochromatosis. The recommended method of the Czech Hepatologic Society of the Czech Medical Society of J. E. Purkyne. Vnitr Lek 2006; 52(2): 173-5.

11. Jaquet P, Codaccioni JL, Fabre M, Marquier A. Fatal complication after 2 bleedings during the treatment of hemochromatosis. Diabete 1967; 15(1): 70-2. French.

12. Lánská M, Vališ M, Bláha M, Strnadová B, Malý J. Therapeutic Plasmapheresis in neurology - our experience. Aktuality z Nefrologie 2010; 16(2): 44-50.

13. Luten M, Roerdinkholder-Stoelwinder B, Rombout-Sestrienkova E, de Grip WJ, Bos HJ, Bosman GJ. Red cell concentrates of hemochromatosis patients comply with the storage guidelines for transfusion purposes. Transfusion 2008; 48(3): $436-41$

14. Mariani R, Pelucchi S, Perseghin P, Corengia C, Piperno A. Erythrocytapheresis plus erythropoietin: an alternative therapy for selected patients with hemochromatosis and severe organ damage. Haematologica 2005; 90(5): 717-8.

15. Moirand R, Adams PC, Bicheler V. Brissot P, Deugnier Y. Clinical features of genetic haemochromatosis in women compared to men. Ann Intern Med 1997; 127: $105-10$.

16. Muncunill J, Vaquer P, Galmes A, Obrador A et al. In hereditary hemochromatosis, red cell apheresis removes excess iron twice as fast as manual whole blood phlebotomy. J Clin Apheresis 2002; 17(2): 88-92

17. Niederau C. Hereditary hemochromatosis. Med Klin (Munich) 2009; 104(12): 931-46.

18. Pietrangelo A. Hereditary hemochromatosis: pathogenesis, diagnosis, and treatment. Gastroenterology 2010; 139(2): 393-408

19. Popovsky MA. Multicomponent apheresis blood collection in the United States: Current status and future directions. Transf Apher Sci 2005; 32: 299-304.

20. Poullin P, Lefèvre PA. Effectiveness of therapeutic erythrocytapheresis to achieve iron depletion in hereditary type 1 hemochromatosis: report of 30 cases. Transfus Clin Biol 2011; 18(5-6): 553-8.

21. Rombout-Sestrienkova E, Nieman FH, Essers BA, van Noord PA, Janssen MC, van Deursen CT, Bos LP, Rombout F, van den Braak R, de Leeuw PW, Koek GH. Erythrocytapheresis versus phlebotomy in the initial treatment of HFE hemochromatosis patients: results from a randomized trial. Transfusion 2012; 52(3): $470-477$.

22. Rombout-Sestrienkova E, van Noord PA, van Deursen CT, Sybesma BJ, Nillesen-Meertens AE, Koek GH. Therapeutic erythrocytapheresis versus phlebotomy in the initial treatment of hereditary hemochromatosis - A pilot study. Transfus Apher Sci. 2007 Jun; 36(3): 261-7.

23. Rombout-Sestrienkova E, van Noord PA, Reuser E, Heeremans J, van Deursen CT, Janssen M, Koek GH. Therapeutic Erythrocytapheresis (TE) versus phlebotomy $(\mathrm{P})$ in the treatment of hereditary hemochromatosis $(\mathrm{HH})$ patients: preliminary results from an ongoing randomized clinical trial (NCT 00202436). Transf Apher Sci 2009; 40: 135-136.

24. Røsvik AS, Ulvik RJ, Wentzel-Larsen T, Hervig T. Blood donors with hereditary hemochromatosis. Transfusion 2010; 50(8): 1787-93.

25. Schultzki T, Seidel K, Storch H et al. A prospective mutlicentre study on the safety of long-term intensive plasmapheresis in donors (SIPLA). Vox Sang 2006; 91: $162-73$

26. Sheahan O, O'Connell E. Hereditary hemochromatosis: patient support and education. Nursing Standard 2009; 24(3): 49-56.

Received: 28/06/2012

Accepted in revised form: 29/10/2012

\section{Corresponding author:}

Vít Řeháček, MD, Faculty of Medicine and University Hospital, Transfusion Department, Sokolská 581, 50005 Hradec Králové, Czech Republic; e-mail: rehacekv@1fhk.cuni.cz 